\title{
Plant Growth Promotion Efficacy of Indole Acetic Acid (IAA) Produced by a Mangrove Associated Fungi-Trichoderma viride VKF3
}

\author{
Nathan Vinod Kumar ${ }^{1 *}$, K. Subha Rajam ${ }^{2}$ and Mary Esther Rani ${ }^{2}$ \\ ${ }^{1}$ National Institute of Oceanography-CSIR, Rgional Centre, Cochin 682018, Kerala, India \\ ${ }^{2}$ Research Centre, Department of Botany and Microbiology, Lady Doak College, \\ Madurai -625002, Tamil Nadu, India \\ *Corresponding author
}

\section{A B S T R A C T}

\begin{abstract}
Keywords
Indole acetic acid,

Trichoderma viride,

Fungi,

Phytohormones,

Antagonism.

Article Info

Accepted:

20 September 2017

Available Online:

10 November 2017

The microorganisms have been widely used for phytohormone production and in biocontrol of fungal pathogens. In the present study, T. viride VKF3, a mangrove isolate was used for production of auxin IAA under in vitro condition. T. viride VKF3 yielded a high IAA production of $115 \mu \mathrm{g} \mathrm{mL}^{-1}$ with $0.5 \% \mathrm{~L}$-tryptophan. The IAA produced by the isolate was confirmed through Thin layer chromatography (TLC) and High performance liquid chromatographic (HPLC) analysis by comparison with standard IAA. The isolate was also capable of producing extracellular enzymes like cellulase, xylanase along with siderophore production which conditions soil and bioavailability of nutrients. The culture filtrate exhbibited plant growth promotional activity along with enhanced germination percentage. T. viride VKF3 exhibited a maximum inhibition of 82 and $94 \%$ was achieved by against fungal pathogens $F$. oxysporum and A. niger respectively. This report shows a high IAA production using $T$. viride VKF3 with bio-control potential.
\end{abstract}

\section{Introduction}

Indole acetic acid (IAA) is one of the major physiologically active auxins, a product of Ltryptophan metabolism produced by several microorganisms including Plant Growth Promoting Rhizobacteria (PGPR) (Lynch, 1985). The physiological function of IAA includes the production of longer roots with increased number of root hairs and root laterals which are involved in nutrient uptake (Datta and Basu, 2000). Apart from these, IAA is also the principle agents that regulate plant response to changes in environmental conditions (Tuteja, 2007; Malhotra and Srivastava, 2009). The IAA is widely produced by many microorganisms which are mainly dwelling in the rhizosphere of plants. Although IAA in yeast extracts was discovered, its production by filamentous fungi is relatively new. Moreover, reports on the production of phytohormones using fermentation are sparse especially the IAA synthesized by fungi (Yürekli et al., 1999; Chung et al., 2003). Development of biotechnology had evolved new prospects in production of plant growth hormones using fungi (Berry, 1988). Recently, there are many reports upcoming on fungal IAA production. Ünyayar et al., (2000) and Ünyayar (2002), reported exogenous IAA production by Phanerochaete chrysosporium strain ME446 
and Funalia trogii. IAA production is mainly dependent on L-tryptophan which acts as a physiological precursor. The microorganism such as Streptomyces, Pseudomonas and Bacillus were found capable of synthesising IAA by utilizing L- tryptophan through indole -3- pyruvic acid pathway (Patten and Glick, 1996; Shanmugaiah et al., 2009; Charulatha et al., 2013). Though advancement in researches finally obtained many fungal isolates with IAA production ability, their physiological role remains unclear. One of the roles suggested for production of IAA by fungus is to mediate fungal-plant interaction. A high concentration of IAA inhibited the hypersensitive response (Robinette and Matthysse, 1990; Jouanneau et al., 1991) and suppressed the expression of plant defense genes (Yamada et al., 1985; Shinshi et al., 1987). The present study focuses on production and characterization of IAA produced by the isolate $T$. viride VKF3. The plant growth promotional activity as well as its biocontrol efficacy against the fungal pathogens were also evaluated.

\section{Materials and Methods}

\section{Isolation and screening for IAA production}

Sediment samples were collected along with plant debris from Valanthakad Mangrove ecosystem, Kerala, India. Serial dilution was performed (upto $10^{-6}$ ) and plated onto potato dextrose agar medium. The inoculated plates were incubated at $28 \pm 2{ }^{\circ} \mathrm{C}$ for 3-5 days. Distinct fungal colonies were purified using spot inoculation. The IAA producing ability of the isolates were screening using the basal medium supplemented with $0.5 \mathrm{mgmL}^{-1}$ of $\mathrm{L}$ -tryptophan. Positive strains were cultured in submerged fermentation culture and incubated at $28 \pm 2^{\circ} \mathrm{C}$ under shaking condition (120 rpm) for 3 days and the culture broth was retrieved after incubation period for IAA quantification.

\section{IAA production using Trichoderma viride VKF3}

Following the incubation time, culture was centrifuged and the supernatant was mixed with Salkowski's reagent $(150 \mathrm{ml}$ of concentrated $\mathrm{H}_{2} \mathrm{SO}_{4}, 250 \mathrm{ml}$ of distilled water, $7.5 \mathrm{ml}$ of $0.5 \mathrm{MFeCl}_{3} \cdot 6 \mathrm{H}_{2} \mathrm{O}$ ) with a $1: 2$ $(\mathrm{v} / \mathrm{v})$ ratio, and was allowed to stand at room temperature for $20 \mathrm{~min}$. The pink color developed, indicating IAA production, was measured at $530 \mathrm{~nm}$ with a spectrophotometer (Double beam UV-Vis Spectrophotometer 2022). Concentration of IAA was calculated using a standard curve prepared with standard IAA. The experiment was carried out in triplicate and values were expressed as mean \pm S.D unless otherwise mentioned. The effect of L-tryptophan concentrations on IAA production was studied using potato dextrose broth medium supplemented with Ltryptophan at concentrations of $0.1,0.5,1$, and $1.5 \%$. The culture was incubated at $28^{\circ} \mathrm{C}$ in a shaker at $120 \mathrm{rpm}$ for 7 days.

\section{Extraction and Characterization of IAA}

Crude IAA was extracted using extraction method described by Harikrishnan et al., (2014). The fractions (10 - 20 micro litter) and standard IAA were placed on TLC plates (silica gel G f254 thickness $0.25 \mathrm{~mm}$ ). TLC was run by using solvent system benzene: $\mathrm{n}$ butanol: acetic acid in 70:25:5 proportion and spots were detected by spraying the plates using Salkowaski reagent. Rf value of the standard and IAA produced by the isolate was calculated. Partial purification of Indole Acetic Acid from crude extract was done by using silica gel column chromatography and fractions were collected with solvent system ethyl acetate and hexane (20:80 v/v). Each fraction was tested in thin layer chromatography and then developed with Salkowski reagent. HPLC analysis of IAA was carried out usig the method described 
earlier by Harikrishnan et al., (2014). Briefly, on a C18 column $(5 \mu \mathrm{m} ; 25 \times 0.46 \mathrm{~cm})$ by using HPLC grade acetonitrile- water system containing $0.1 \%$ trifluoroacetic acid was programmed over $30 \mathrm{~min}$ at a flow rate of $0.5 \mathrm{~mL} / \mathrm{min}$ with UV detector at $220 \mathrm{~nm}$ at $40^{\circ} \mathrm{C}$. Mobile phase consisted of methanol and water $(80: 20 \mathrm{v} / \mathrm{v})$ run at flow rate was analysed by comparison with the elution profiles of those authentic IAA injected separately.

Screening for extracellular enzyme and siderophore production

All fungal isolates were checked for their ability to produce cellulase enzyme on PDA media supplemented with $2 \%$ carboxy methyl cellulose (CMC) (Lingappa and Lockwood, 1962).Cellulolytic fungi exhibited a clearing zone around the colony when medium was supplemented with $0.2 \%$ congo red and destained with $1 \mathrm{M} \mathrm{NaCl}$ solution after incubation for 3 to 5 days. Assay for positive isolates were performed to select the isolate with highest cellulolytic activity using potato dextrose broth under similar growth conditions using the standard method described in the following section. Xylanase screening for fungal isolate was performed on PDA plates supplemented with $2 \%$ birch wood xylan (BWX) and the incubated plates were flooded with iodine solution to observe clear zone around positive colonies (Charitha and Sunil, 2013).

Lipase screening for fungal isolates was performed using PDA plates supplemented with $1 \%$ olive oil and $0.5 \%$ phenol red indicator. Lipase enzyme degrades oil to release free fatty acids which changed the medium $\mathrm{pH}$ and the medium colour changed from red to yellow. Laccase activity was assessed by a modified method proposed by Hankin and Anagnostakis (1975). The fungi were grown on PDA agar medium amended with $0.5 \%$ tannic acid and incubated for 3-5 days at $28 \pm 2^{\circ} \mathrm{C}$. On oxidation of tannic acid by laccase, the medium changed a reddish brown. Siderophore production was screened by method described by Harikrishnan et al., (2014).

\section{Plant growth promotion activity}

Seeds of Vigna radiata, Vigna mungo and Sesamum indicum were treated with culture supernatant containing IAA for $30 \mathrm{~min}$. These seeds were air dried and sown into pots containing sterile soil. Seeds treated with distilled water served as control. Various parameters like germination percentage, shoot and root length as well as dry and fresh of the plantlets after 1 week growth was recorded.

\section{Antagonistic Effects}

For understanding the antagonistic effect against the pathogenic fungi, two discs $(6 \mathrm{~mm}$ in the diameter) of one week old culture on (PDA), one carrying the stock of the antagonistic agent (Trichoderma viride)and the other the pathogenic agent were then placed at the periphery of Petri plate at the same distance on PDA medium. One disc of each pathogenic agent was maintained as control. Each replicates has three plates. The inoculated plates were incubated at $25^{\circ} \mathrm{C}$ for four days, and measurement of radial mycelia of the fungus were taken every $24 \mathrm{hrs}$. The percentage growth inhibition (I) was calculated using the formula $\mathrm{I}(\%)=(1-\mathrm{T}$ /C) $x$ 100, where: I=Percentage inhibition of pathogen by antagonists. $\mathrm{C}=$ Radial growth in control, $\mathrm{T}=$ Radial growth in the treatment.

\section{Results and Discussion}

\section{Isolation and screening of actinomyctes}

In this study, about 15 different fungal colonies were obtained from mangrove 
sediment samples. Among the same, 4 isolates were positive for IAA production. Based on the secondary screening (quantification of IAA), the VKF3 isolate was found to be potential for IAA production. The isolate VKF3 was identified as Trichoderma viride based on lactophenol cotton blue (LCB) mount staining, colony morphology and molecular identification using D1-D2 region amplification (Nathan et al., 2014). The fungal isolates produced many phytohormones which are essential for plant fungus interaction including the mechanism of pathogenesis or symbiotic strategies, leading to plant growth promotion and basal plant defense mechanism modification ( $\mathrm{Fu}$ et al., 2015). Many Trichoderma species were able to produce the auxin phytohormone indole-3-acetic acid (IAA), and its production has been suggested to promote root growth. Nieto-Jacobo et al., (2017) reported Trichoderma sp. namely $T$. virens $\mathrm{Gv} 29.8, T$. atroviride IMI206040, $T$. sp. "atroviride $B^{\prime \prime} \mathrm{LU} 132$, and $T$. asperellum LU1370 with ability to synthesize volatile plant gwoth promoting factors. Similarly, $T$. harzianum was found to enhance root growth and plant development which was attributed to the unidentified growth-regulating factors by the fungus (Windham et al., 1986; Harman et al., 2004).

\section{Effect of L- tryptophan concentration on IAA production}

IAA production in microbes is mainly mediated through indole-3-pyruvate acid and tryptamine which uses tryptophan as substrate (Tudzynski and Sharon, 2002). Tryptophan supplementation enhanced the biosynthesis of IAA by many folds by the increased availability of substrate. To evaluate the effect of tryptohan on IAA production, different concentrations of L- tryptophan between 0.1 to $1.5 \%$ were supplemented in the medium. The spectrophotometric analysis showed that gradual increase in the IAA production with respective L-tryptophan concentration (Fig. 1). The maximum IAA production observed by $T$. viride VKF3 was $115 \mu \mathrm{gmL}^{-1}$ when the medium was amended with $0.5 \%$ Ltryptophan. However, the very high concentration of L- tryptophan lowered IAA production which was supported by Harikrishnan et al., (2014) who observed an adverse effect on IAA production by the isolate Streptomyces sp VSMGT1014 with high tryptophan concentrations. Difference in IAA production among fungal isolates was observed by many researchers. Yadav et al., (2011) reported, IAA production using various fungal isolates like Aspergillus niger $\left(85 \mu \mathrm{g} \mathrm{mL}^{-1}\right)$ and T. harzianum $\left(68 \mu \mathrm{g} \mathrm{mL}^{-1}\right)$ and Penicillium citrinum $\left(52 \mu \mathrm{g} \mathrm{mL}^{-1}\right)$ with 3 days of incubation at $30^{\circ} \mathrm{C}$. The results observed in the present study were very high compared to these reports. The better IAA production was achieved at $28^{\circ} \mathrm{C}$ which was supported by Gunasekaran, (1978) and Hasan, (2002) who also observed a similar high IAA production trend at this incubation temperature. Similarly, IAA production using Streptomyces $s p$ was also high at the optimal temperature range of $25-30^{\circ}$ (Aldesuquy et al., 1998; Khamna et al., 2010). Moreover, Gravel et al., (2007), also yielded a maximum IAA of only $6.2 \mu \mathrm{g} \mathrm{mL}^{-1}$ in the presence of $200 \mu \mathrm{g} \mathrm{mL} \mathrm{m}^{-1}$ tryptophan using Trichoderma atroviride. The tryptophan induced enhancement of IAA production was supported by previous reports also (Patten and Glick, 1996; Shanmugaiah et al., 2009; Charulatha et al., 2013).

\section{Characterization of IAA}

The IAA produced by $T$. viride VKF3 was characterized by TLC and HPLC analysis. As shown in Figure 2b, when the TLC plate was treated with Ehmann reagent, the ethyl acetate extract from culture filtrate showed a clear pink colour spot on the TLC plate at the Rf 
value corresponding to standard IAA (0.62). Thin layer chromatography findings were in agreement with the previous reports (Ahmad et al., 2005). Similarly, HPLC analysis was conducted to identify and quantify the IAA production precisely. As shown in Figure 2a, ethyl acetate extract from the culture filtrate of the strain and corresponding reference authentic standard showed peak at the similar retention time $(4.967 \mathrm{~min})$.

\section{Extracellular Enzyme Production by Fungus}

Extracellular enzymes produced by the fungal strains also help in conditioning of the soil for the better plant growth. Hence, we screened the extracellular enzyme production (qualitative). T.viride VKF3 was protential for cellulase, xylanse and laccase production (Table 1). However, there was no lipase activity observed. This hypothesis was in hand with a previous study (Jog et al., 2012), where the extracellular enzyme produced by the Actinomycete isolates were found to be capabale of utilizing the nutrients and in turn exhibit PGP activities that were extremely beneficial for plants. Moreover, the isolate T.viride VKF3 was capable of siderophore production also. Anke et al., (1991) reported the efficiency of $T$. longibrachiatum and $T$. Pseudoko ningii for producing siderophores under iron deficienct conditions. This was also supported by reports of Vinale et al., (2013), who identified harzianic acid, a novel siderophore from Trichoderma harzianum.

Fig.1 Effect of L-tryptophan concentration on IAA production by Trichoderma viride VKF3




Fig.2 Characterization of IAA produced by Trichoderma viride VKF3

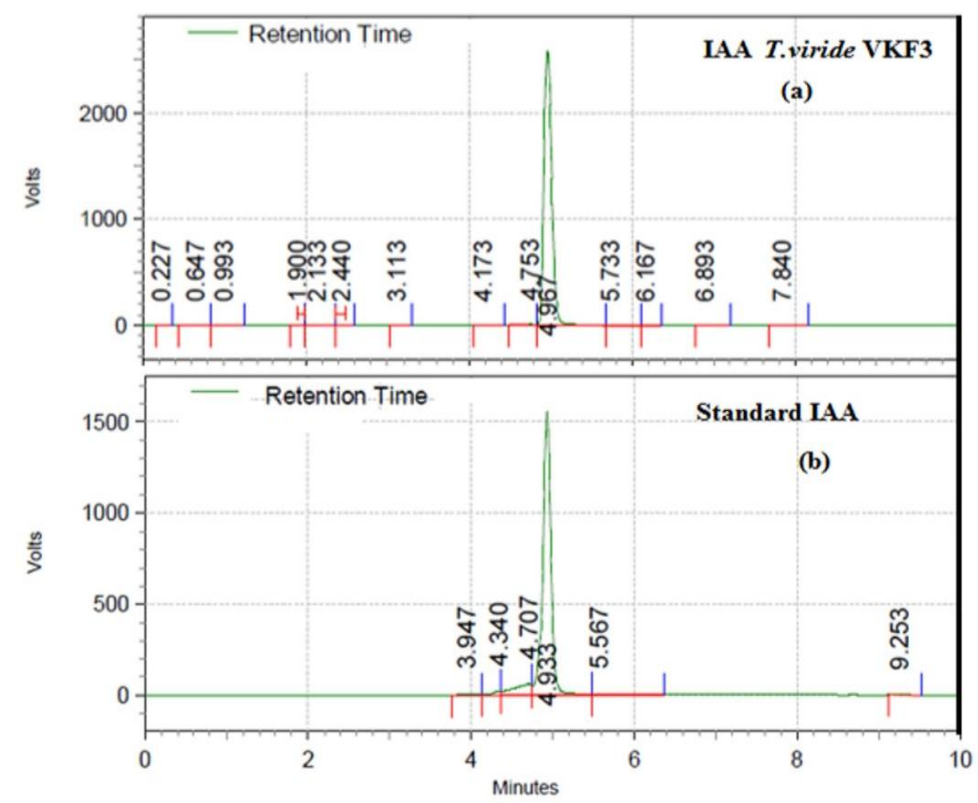

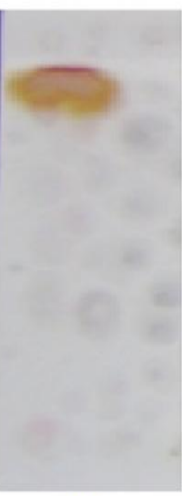

(c)

a) HPLC chromatogram of IAA by T.viride VKF3 and b) standard IAA

c) Thin layer chromatogram of IAA produced by $T$. viride VKF3

Fig.3 Evaluation of plant growth promotional activity of IAA produced by Trichoderma viride VKF3
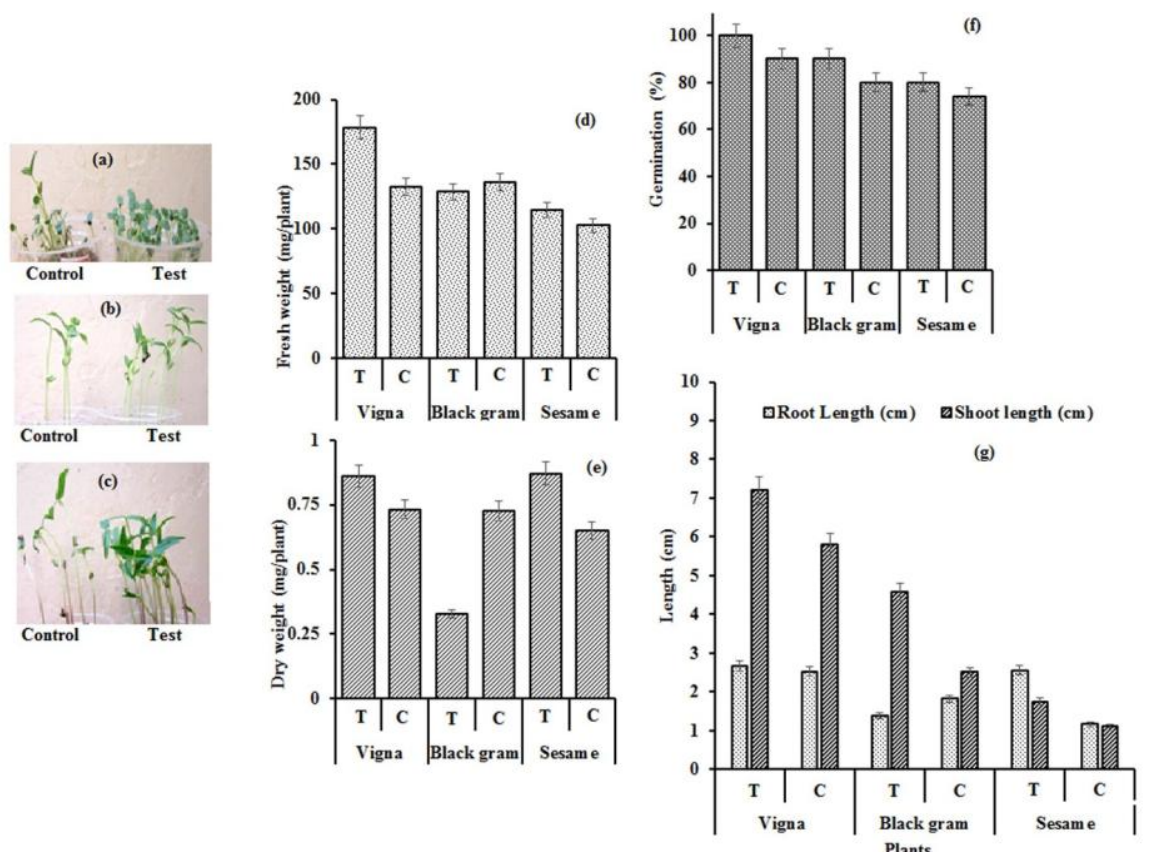

Experimental setup: a) Sesamum indicum b) Vigna radiate and c) Vigna mungo

d) Effect of IAA treatment on fresh weight e) Effect of IAA treatment on dry weight

f) Effect of IAA treatment on Germination percentage and g) Effect of IAA treatment on shoot and root length 
Table.1 Screening for extracellular enzymes production by T. viride VKF3

\begin{tabular}{lc}
\hline Parameters & Results \\
\hline Siderophore & ++ \\
Cellulase & ++ \\
Xylanase & ++ \\
Laccase & + \\
Lipase & - \\
\hline
\end{tabular}

\section{Plant Growth Promotion Efficiency}

Vigna radiata, Vigna mungo and Sesamum indicum were used for the evaluation of plant growth promotion efficiency. The Figure 3a-c depicted the experimental setup of plant growth promotional activity, where there was enhanced growth in IAA treated plants compared to control. The fresh weight and dry weight of the three plants were noted and was also found to be increased during IAA treatment (Fig. 3d and e). Germination percentage also was found to increase by IAA treatment (Fig. 3f). Maximum germination was observed in case of $V$. radiata followed by $V$. mungo and $S$. indicum. Root and shoot length of treated plants were found to have an increasing trend. Shoot length of $V$. radiata was enhanced during the treatment (Fig. 3g). However, no much change was observed in case of root length. In case of S. indicum, both root and shoot length was increased compared to control plant treated with distilled water. The present report was in agreement with the previous report of Harikrishnan et al., (2014), who observed that IAA from Streptomyces $s p$ VSMGT1014 substantially increased seed germination, root length and shoot length. Moreover, dry weight and vigor index of the tested rice plants were also significantly increased by the isolate VSMGT1014 compared to control.

\section{Antagonistic Activity of T. viride VKF3}

Antagonistic effect of $T$. viride VKF3against two fungal plant pathogens, Fusarium oxysporum and Aspergillus niger was evaluated. Maximum inhibition of 82 and 94\% was achieved by $T$. viride VKF3 against $F$. oxysporum and $A$. niger respectively. Harikrishnan et al., (2014) also reported the efficacy of microorganisms for biocontrol of fungal pathogen with IAA production. Similar reports were available on production of IAA and antagonistic mechanism of five streptomyces strain isolated from rice rhizosphere having biocontrol potential against Fusarium wilt disease in chickpea and also having Plant growth promoting traits (PGPT) such as IAA and siderophore production (Gopalakrishnan et al., 2011).

T. viride $\mathrm{VKF} 3$, a mangrove isolate was effeicient for high IAA production upto was $115 \mu \mathrm{g} \mathrm{mL}^{-1}$ with $0.5 \%$ L-tryptophan. The IAA produced by the isolate was confirmed through TLC and HPLC analysis by comparison with standard IAA. The isolate was also capable of producing extracellular enzymes like cellulase, xylanase along with siderophore production. The culture filtrate exhibited plant growth promotional activity along with enhanced germination percentage. $T$. viride VKF3 exhibited a maximum inhibition of 82 and $94 \%$ was achived by against fungal pathogens $F$. oxysporum and $A$. niger respectively. This report shows a high IAA production using $T$. viride VKF3 with bio-control potential.

\section{Acknowledgement}

The Authors are thankful to Department of Science and Technology, Government of India and TNSCST for providing the grant to 
facilitate the research [Sanction order no. DST/SSTP/TN/2K 10/126(G) 13-09-2011]. Authors thank Management and Department of Botany and Microbiology, Lady Doak College, Madurai for providing the facilities and supporting the work. NVK acknowledge the financial support of Science and Engineering Board (SERB), Government of India through National Post-Doctoral fellowship [PDF/2016/000438].The authors declare that they have no conflict of interest.

\section{References}

Ahmad, F., I. Ahmad,and M.S. Khan. 2005. Indole acetic acid production by the indigenous isolates of Azotobacter and fluorescent Pseudomonas in the presence and absence of tryptophan. Turkish Journal of Biology29:29-34.

Aldesuquy, H. S., F.A. Mansour, and S.A. Abo-Hamed. 1998. Effect of the culture filtrates of Streptomyces on growth and productivity of wheat plants. Folia Microbiologica43: 465-470.

Anke, H., J. Kinn, K.E. Bergquist, and O. Sterner. 1991. Production of siderophores by strains of the genus Trichoderma. Biology of metals4: 176180.

Berry, D. R. 1988. Physiology of industrial fungi. Blackwell Scientific Publications.

Charitha, M. D., and M. Sunil Kumar. 2013. Production, optimization and partial purification of cellulase by Aspergillus niger fermented with paper and timber sawmill industrial wastes. Journal of microbiology and biotechnology research, 2: 120-128.

Charulatha, R., H. Harikrishnan, P.T.Manoharan, and V.Shanmugaiah. 2013. Characterization of groundnut rhizosphere Pseudomonas sp. VSMKU 2013 for control of phytopathogens. In: Microbiological Research In
Agroecosystem Management, Springer India. 121-127

Chung, K. R., T. Shilts, U.Ertürk, L.W. Timmer, and P.P. Ueng. 2003. Indole derivatives produced by the fungus Colletotrichum acutatum causing lime anthracnose and postbloom fruit drop of citrus. FEMS Microbiology Letters 226: 23-30.

Datta, C., and P.S.Basu. 2000. Indole acetic acid production by a Rhizobium species from root nodules of a leguminous shrub, Cajanus cajan. Microbiological research 155: 123-127.

Fu, S. F., J.Y. Wei, H.W. Chen, Y.Y. Liu, H.Y. Lu, andJ.Y. Chou. 2015. Indole-3acetic acid: A widespread physiological code in interactions of fungi with other organisms. Plant signaling and behavior 10: e1048052.

Gopalakrishnan, S., S. Pande, M. Sharma, P.Humayun, B.K. Kiran, D. Sandeep, M.S.Vidya, K. Deepthi, and O. Rupela. 2011. Evaluation of actinomycete isolates obtained from herbal vermicompost for the biological control of Fusarium wilt of chickpea. Crop Protection, 30: 1070-1078.

Gravel, V., H. Antoun, and R.J. Tweddell. 2007. Growth stimulation and fruit yield improvement of greenhouse tomato plants by inoculation with Pseudomonas putida or Trichoderma atroviride: possible role of indole acetic acid (IAA). Soil Biology and Biochemistry39: 1968-1977.

Gunasekaran, M. 1978. Physiological studies on Phymatotrichum omnivorum. IX. Synthesis of indole acetic acid in vitro. Microbios 22: 85-91.

Hankin, L., and S.L. Anagnostakis. 1975. The use of solid media for detection of enzyme production by fungi. Mycologia 597-607.

Harikrishnan, H., V. Shanmugaiah, and N. Balasubramanian. 2014. Optimization 
for production of Indole acetic acid (IAA) by plant growth promoting Streptomyces sp VSMGT1014 isolated from rice rhizosphere. Int. J. Curr. Microbiol. Appl. Sci. 3: 158-171.

Harman, G. E., M. Lorito, and J.M. Lynch. 2004. Uses of Trichoderma spp. to alleviate or remediate soil and water pollution. Advances in applied microbiology 56: 313-330.

Hasan, H. A. H. 2002. Gibberellin and auxin production by plant root-fungi and their biosynthesis under salinity-calcium interaction. Rostlinnav yroba 48: 101106.

Jog, R., G. Nareshkumar, and S. Rajkumar. 2012. Plant growth promoting potential and soil enzyme production of the most abundant Streptomyces spp. from wheat rhizosphere. Journal of applied microbiology 113: 1154-1164.

Jouanneau, J. P., D. Lapous, and J. Guern. 1991. In plant protoplasts, the spontaneous expression of defense reactions and the responsiveness to exogenous elicitors are under auxin control. Plant physiology 96: 459-466.

Khamna, S., A. Yokota, J.F. Peberdy, and S. Lumyong. 2010. Indole-3-acetic acid production by Streptomyces sp. isolated from some Thai medicinal plant rhizosphere soils. Eur Asian Journal of BioSciences4.

Lingappa, B. T., and J.L. Lockwood. 1962. Fungi toxicity of lignin monomers, model substances, and decomposition products. Phytopathology 52: 295.

Lynch, J. M. 1985. Origin, nature and biological activity of aliphatic substances and growth hormones found in soil. In: Soil organic matter and biological activity, Springer Netherlands 151-174.

Malhotra, M., and S.Srivastava. 2009. Stressresponsive indole-3-acetic acid biosynthesis by Azospirillum brasilense
SM and its ability to modulate plant growth. European Journal of Soil Biology 45: 73-80.

Nathan, V. K., M.E. Rani, G. Rathinasamy, K.N. Dhiraviam, and S. Jayavel. 2014. Process optimization and production kinetics for cellulase production by Trichoderma viride VKF3. Springer Plus, 3(1), 92.

Nieto-Jacobo, M.F., J.M. Steyaert, F.B. Salazar-Badillo, D.V. Nguyen, M. Rostás, M. Braithwaite, J.T. De Souza, J.F. Jimenez-Bremont, M. Ohkura, A. Stewart, andA. Mendoza-Mendoza. 2017. Environmental growth conditions of Trichoderma spp. affects indole acetic acid derivatives, volatile organic compounds, and plant growth promotion. Frontiers in plant science 8.

Patten, C. L., and B.R. Glick. 1996. Bacterial biosynthesis of indole-3-acetic acid. Canadian journal of microbiology 42: 207-220.

Robinette, D., and A.G. Matthysse. 1990. Inhibition by Agrobacterium tumefaciens and Pseudomonas savastanoi of development of the hypersensitive response elicited by Pseudomonas syringaepv. phaseolicola. Journal of bacteriology 172: 5742-5749.

Shanmugaiah, V., N. Balasubramanian, S. Gomathinayagam, P.T.Manoharan, and A. Rajendran, 2009. Effect of single application of Trichoderma viride and Pseudomonas fluorescens on growth promotion in cotton plants. African Journal of Agricultural Research 4: 1220-1225.

Shinshi, H., D. Mohnen, and F.Meins, 1987. Regulation of a plant pathogenesisrelated enzyme: inhibition of chitinase and chitinase mRNA accumulation in cultured tobacco tissues by auxin and cytokinin. Proceedings of the National Academy of Sciences 84: 89-93.

Tudzynski, B., and A. Sharon, 2002. 
Biosynthesis, biological role and application of fungal phytohormones. In: Industrial Applications, Springer Berlin Heidelberg 183-211.

Tuteja, N. 2007. Abscisic acid and abiotic stress signaling. Plant signaling and behavior 2: 135-138.

Ünyayar, S. 2002. Changes in abscisic acid and indole-3-acetic acid concentrations in Funaliatrogii (Berk.) Bondartsev \& Singer and Phanerochaete chrysosporium Burds. ME446 subjected to salt stress. Turkish Journal of Botany 26: 1-4.

Ünyayar, S., E. Ünal, and A. Ünyayar. 2000. Production of auxin and abscisic acid by Phanerochaete chrysosporium ME446 immobilized on polyurethane foam. Turkish Journal of Biology 24: 769-774.

Vinale, F., M. Nigro, K. Sivasithamparam, G. Flematti, E.L. Ghisalberti, M. Ruocco, R. Varlese, R. Marra, S. Lanzuise, A.
Eid, and S.L. Woo. 2013. Harzianic acid: a novel siderophore from Trichoderma harzianum. FEMS microbiology letters. 347:123-129.

Windham, M. T., Y. Elad, and R. Baker. 1986. A mechanism for increased plant growth induced by Trichoderma spp. Phytopathology 76: 518-521.

Yamada, T., C. Palm, B. Brooks, and T. Kosuge. 1985. Nucleotide sequences of the Pseudomonas savastanoi indole acetic acid genes show homology with Agrobacterium tumefaciens TDNA. Proceedings of the National Academy of Sciences 82: 6522-6526.

Yürekli, F., O. Yesilada, M. Yürekli, and S.F. Topcuoglu. 1999. Plant growth hormone production from olive oil mill and alcohol factory wastewaters by white rot fungi. World Journal of Microbiology and Biotechnology 15: 503-505.

\section{How to cite this article:}

Nathan Vinod Kumar, K. Subha Rajam and Mary Esther Rani. 2017. Plant Growth Promotion Efficacy of Indole Acetic Acid (IAA) Produced by a Mangrove Associated Fungi-Trichoderma viride VKF3. Int.J.Curr.Microbiol.App.Sci. 6(11): 2692-2701. doi: https://doi.org/10.20546/ijcmas.2017.611.317 